\title{
Debris flow impact assessment caused by 14 April 2012 rainfall along the Al-Hada Highway, Kingdom of Saudi Arabia using high-resolution satellite imagery
}

\begin{abstract}
The Al-Hada highway that descends towards the west of the city of At-Taif is a major connecting highway in the western part of the Kingdom of Saudi Arabia. It is one of the series of descending roads connecting the holy city of Makkah and the city of Jeddah with the city of At-Taif and the cities farther south along the escarpment. The length of the Al-Hada highways is about $22 \mathrm{~km}$. The Al-Hada highway has been historically exposed to landslides and other geohazards since the day it was opened to public some 60 years ago. The road has been reconstructed and many slope instabilities have been remediated and the road has been expanded to two lanes in each direction. Heavy rainfalls occurred on the 14th of April 2012 in the province of At-Taif, causing huge debris flows in two places along the Al-Hada highway. As a result of that, these debris flows closed all four lanes of the highway for 2 weeks in order to remove the debris. The current research deals with mapping of all debris flows along Al-Hada highway and determining their volumes and their impact on the road. Finally, suitable solutions have been suggested to address these critical sites to minimize and/or avoid the debris flow hazards in the future.
\end{abstract}

Keyword: Debris flow; Geographic information systems (GIS); KSA; Landslide; Mitigation methods; Remote sensing; Volume estimation 